NOTES

\title{
Covalent Immobilization of Glucose Oxidase on Film Prepared by Electrochemical Copolymerization of Thiophene-3-acetic Acid and 3-Methylthiophene for Glucose Sensing
}

\author{
Masato Shimomura, Naoyuki KoJIma, Kenji Oshima, \\ Takeshi YAMAUCHI, and Shinnosuke MiYAUCHI \\ Department of Bioengineering, Faculty of Engineering, \\ Nagaoka University of Technology, 1603-1 Kamitomioka-machi, \\ Nagaoka 940-2188, Japan
}

(Received February 6, 2001; Accepted May 23, 2001)

\begin{abstract}
KEY WORDS Glucose Oxidase / Thiophene-3-acetic Acid / 3-Methylthiophene / Enzyme / Immobilization / Sensor /
\end{abstract}

Conducting polymers were synthesized by electrochemical polymerization of such heterocyclic compounds as furans, azulenes, pyrroles and thiophenes. Immobilization of enzymes in these conducting polymers by electrochemical polymerization is an attractive technique for fabricating micro enzyme-electrodes, ${ }^{1,2}$ which can be applied to in vivo and in vitro measurement as biosensors in clinical analyses. ${ }^{3-5}$

The authors made enzyme-electrodes by covalent immobilization of enzyme on conducting polymer films ${ }^{6,7}$ whereas conventional immobilization is carried out by physical entrapment of enzyme during electrochemical polymerization in the presence of enzyme. ${ }^{8,9}$ Considering that an enzyme reaction occurs on enzyme-electrode/bulk solution interface, the sensitivity of biosensors is attributed mainly to the enzyme molecules on the surface of conducting polymer layer.

In the present study, the film of polythiophene derivative carrying carboxyl groups was prepared and glucose oxidase (GOD) was immobilized covalently on the film: Thiophene-3-acetic acid (T3A) and 3-methylthiophene (3MT) were electrochemically copolymerized, and GOD was immobilized on resulting copolymer film, i.e., poly $\{[3$-(carboxylmethyl)thiophene-2,5-diyl]- co -(3-methylthiophene-2,5-diyl)\} (T3A-3MT copolymer), by condensation reaction of GOD with carboxyl groups on copolymer film. Amperometric response to glucose was examined using the GOD-immobilized T3A-3MT copolymer film as a glucose sensing electrode.

\section{EXPERIMENTAL}

\section{Materials}

T3A and 3MT were purchased from Tokyo Kasei Kogyo Co., Ltd. and Nacalai Tesque, Inc., respectively. Tetra- $n$-butylammonium tetrafluoroborate was purchased from Nacalai Tesque, Inc. These were of reagent grade and used for electrochemical polymerization without further purification. GOD (EC 1.1.3.4, grade II) was supplied by Toyobo Co. Ltd., which had an activity of 165 units $\mathrm{mg}^{-1}$. Other chemicals were reagent grade or analytical grade commercial materials and used without further purification.

\section{Preparation of T3A-3MT Copolymer Films}

Copolmer 1: Copolymer film was prepared on golddeposited alumina plate $\left(0.25 \mathrm{~cm}^{2}\right)$ by electrochemical copolymerization in $25 \mathrm{~mL}$ of propylene carbonate containing $0.01 \mathrm{M} \mathrm{T} 3 \mathrm{~A}, 0.09 \mathrm{M} 3 \mathrm{MT}$ and $0.1 \mathrm{M}$ tetra- $n$-butylammonium tetrafluoroborate at $+2.2 \mathrm{~V}$ vs. saturated calomel electrode (SCE). A potentiostat/galvanostat (Hokuto Denko Corp. HA-150G) and a coulomb/amperehour meter (Hokuto Denko Corp. HF203D) were used. The amount of passed charge was $0.20 \mathrm{C} \mathrm{cm}^{-2}$. The obtained copolymer film was washed with propylene carbonate and dried in vacuo.

Copolymer 2: Copolymerization was carried out in $25 \mathrm{~mL}$ propylene carbonate containing $0.05 \mathrm{M} \mathrm{T} 3 \mathrm{~A}$ and $0.05 \mathrm{M}$ 3MT. Other conditions were the same as for preparation of Copolymer 1.

IR spectra of the copolymers were measured on a JEOL JIR-7000 spectrometer. Conductivity of the 
copolymer films was measured in the thickness direction by two-probe DC method. Prior to conductivity measurement, gold was deposited on the surface (opposite to the alumina plate) of each film, and ohmic contact of gold electrodes with the film was confirmed.

\section{Immobilization of GOD on T3A-3MT Copolymer Films}

GOD was immobilized on T3A-3MT copolymer films using 1-cyclohexyl-3-(2-morpholinoethyl)carbodiimide metho- $p$-toluene-sulfonate (CMC) as a condensing agent ${ }^{10}$ as follows: In $5 \mathrm{~mL}$ distilled water $50 \mathrm{mg}$ GOD and $120 \mathrm{mg}$ CMC were dissolved and the solution was kept at $4^{\circ} \mathrm{C}$. Each copolymer film was immersed in the solution for $18 \mathrm{~h}$ and rinsed with distilled water.

The amount of immobilized GOD was determined by analysis with Folin-Ciocalteu phenol reagent after alkaline copper treatment according to the method of Lowry. ${ }^{11}$ The activity of GOD was measured at $30^{\circ} \mathrm{C}$ by colorimetric method based on the procedure of Trinder. ${ }^{12}$

\section{Glucose Sensing}

Based on a preceding study, ${ }^{13}$ amperometric response of GOD-immobilized T3A-3MT coplymer film to glucose was measured by applying a constant potential of $+0.4 \mathrm{~V} v s$. SCE in $25 \mathrm{~mL}$ of $0.1 \mathrm{M}$ phosphate buffer ( $\mathrm{pH}$ 7.0) containing $1 \mathrm{mM} p$-benzoquinone as a mediator. After background current was made constant, a given amount of $1 \mathrm{M}$ glucose solution was added to the buffer solution, and current change was monitored with a pen recorder.

\section{RESULTS AND DISCUSSION}

Films of Copolymers 1 and 2 were obtained successfully by electrochemical copolymerization. Figure 1 shows IR spectra of the copolymers together with poly3MT. Prior to IR measurement, the film samples were dedoped electrochemically in propylene carbonate containing $0.1 \mathrm{M}$ tetra- $n$-butylammonium tetrafluoroborate at $0 \mathrm{~V} v s$. SCE till current values became zero, then washed with propylene carbonate, and dried in vacuo. As seen in Figure 1, absorption in the vicinity of $1700 \mathrm{~cm}^{-1}$, corresponding to $\mathrm{C}=\mathrm{O}$ stretching of carboxyl groups, was observed for both copolymers, and absorption of Copolymer 2 was stronger than that of Copolymer 1 . This suggests that Copolymer 2 contains more T3A components than Copolymer 1 though the compositions of the copolymers were not determined quantitatively.

In Table I, conductivities of the copolymer films are compared with that of poly3HT film. It is quite ob-

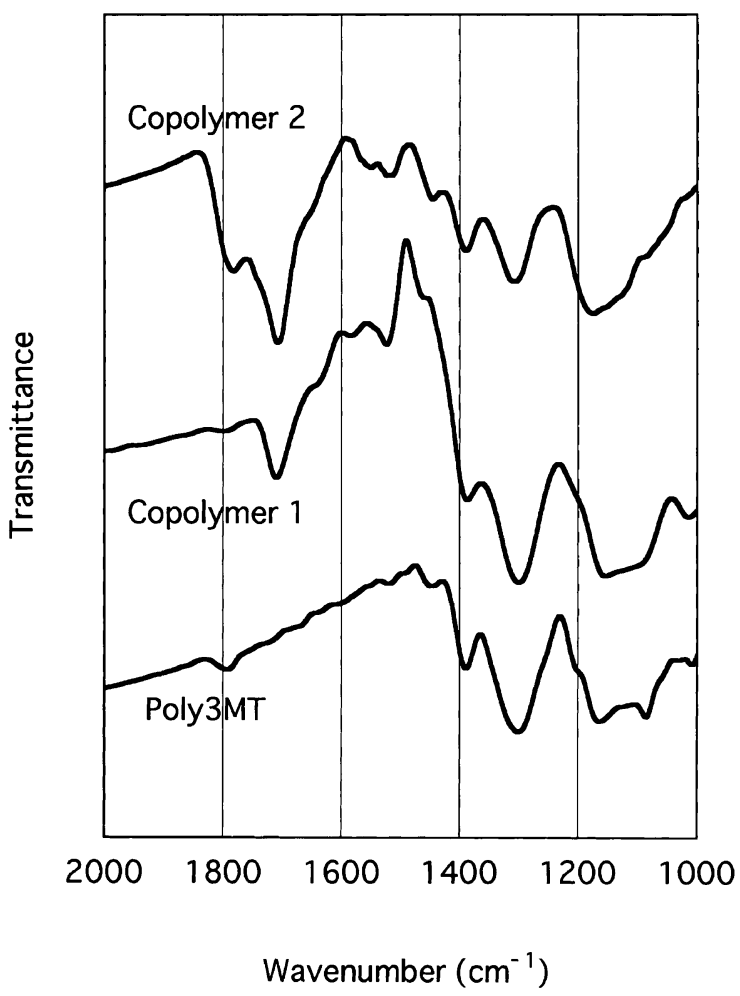

Figure 1. IR spectra of copolymers and poly3MT.

Table I. Conductivity of polymer films

\begin{tabular}{lccc}
\hline \multirow{2}{*}{ Polymer film } & \multicolumn{3}{c}{ Conductivity } \\
\cline { 2 - 3 } & $-30^{\circ} \mathrm{C}$ & $20^{\circ} \mathrm{C}$ & $70^{\circ} \mathrm{C}$ \\
\hline Poly3MT & 20 & 25 & 34 \\
Copolymer 1 & 1.2 & 1.6 & 2.1 \\
Copolymer 2 & $0.5 \times 10^{-3}$ & $1.2 \times 10^{-3}$ & $2.0 \times 10^{-3}$ \\
\hline
\end{tabular}

Table II. Amount and activity of immobilized GOD

\begin{tabular}{|c|c|c|}
\hline Support film & $\frac{\text { GOD immobilized }}{\mu \mathrm{g} \mathrm{cm}^{-2}}$ & $\frac{\text { Activity at } \mathrm{pH} 7.0}{\text { units } \mathrm{cm}^{-2}}$ \\
\hline Copolymer 1 & 21 & 0.56 \\
\hline Copolymer 2 & 22 & 0.63 \\
\hline
\end{tabular}

vious that conductivity decreased with increase in the content of T3A. The conductivity of each polymer film increased with temperature, which is characteristic of semiconductors.

GOD was immobilized covalently on copolymer films by condensation reaction with carboxyl groups on the films. The amount and activity of immobilized GOD are given in Table II. Although IR data in Figure 1 show that Copolymer 2 contains more carboxyl groups than Copolymer 1, few differences in amount and activity were observed for GOD immobilized on the films of Copolymers 1 and 2. Therefore, it is considered that only a small quantity of the carboxyl groups on the copolymer films took part in immobilization of GOD probably due to large molecular size of GOD.

The effect of $\mathrm{pH}$ on the activity of the immobilized 


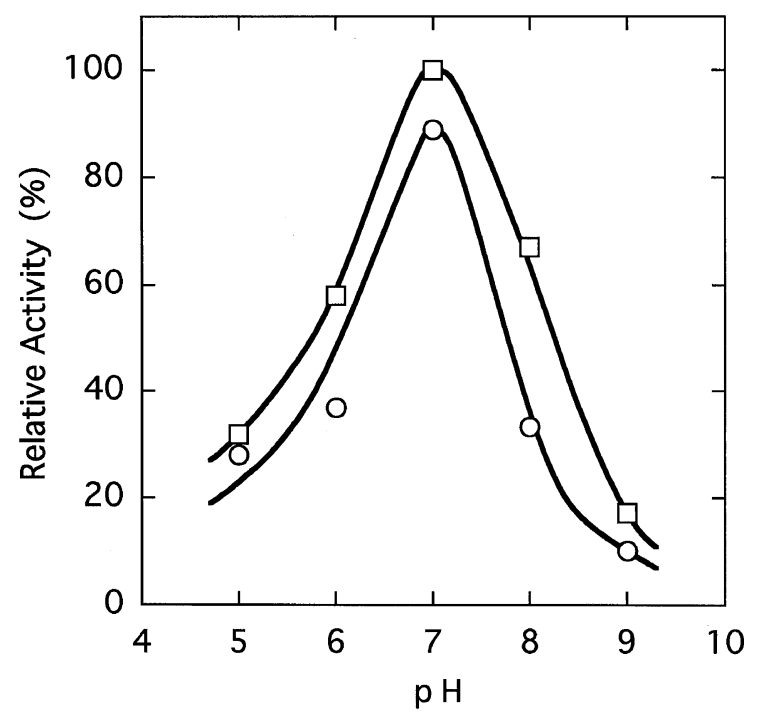

Figure 2. Effect of $\mathrm{pH}$ on activity of GOD immobilized on film of Copolymer 1, $\bigcirc$; Copolymer 2, $\square$.

GOD is shown in Figure 2, where the activity of GOD on copolymer films over the range of $\mathrm{pH} 5.0-9.0$ is given as the ratio to that of the GOD on the film of Copolymer 2 at $\mathrm{pH} 7.0$ in terms of relative activity. Optimum $\mathrm{pH}$ for GOD immobilized on copolymer films was in the vicinity of $\mathrm{pH} 7.0$ whereas optimum $\mathrm{pH}$ for native GOD was between 5.0 and 7.0. ${ }^{14,15}$ Taking optimum $\mathrm{pH}$ into account, glucose sensing with GODimmobilized copolymer films was carried out in phosphate buffer of $\mathrm{pH}$ 7.0. The GOD-immobilized copolymer films showed rapid response to incremental addition of $1 \mathrm{M}$ glucose solution, and current became almost constant within $30 \mathrm{~s}$ after addition of the glucose solution. Plots for response current at $30 \mathrm{~s}$ after each addition of glucose against the concentration of glucose are shown in Figure 3. Response current was proportional to the concentration of glucose, and the plots gave straight lines with slopes of 2.0 and $2.5 \mu \mathrm{A}$ per $1 \mathrm{mM}$ glucose for GOD-immobilized films of Copolymers 1 and 2, respectively. It is interesting to note that the slope, i.e., glucose sensitivity, did not depend on conductivity of copolymer films (Table I) but on activity of immobilized GOD (Table II).

The present study demonstrates that GOD is immobilized on T3A-3MT copolymer films using CMC as condensing agent and GOD-immobilized copolymer films respond amperometrically to glucose. The amount and activity of immobilized GOD were hardly controlled by the content of carboxyl groups in the copolymer films. Glucose sensitivity of GOD-immobilized copolymer films was found to reflect the activity of immobilized GOD. Sensitivity was not affected by the conductivity

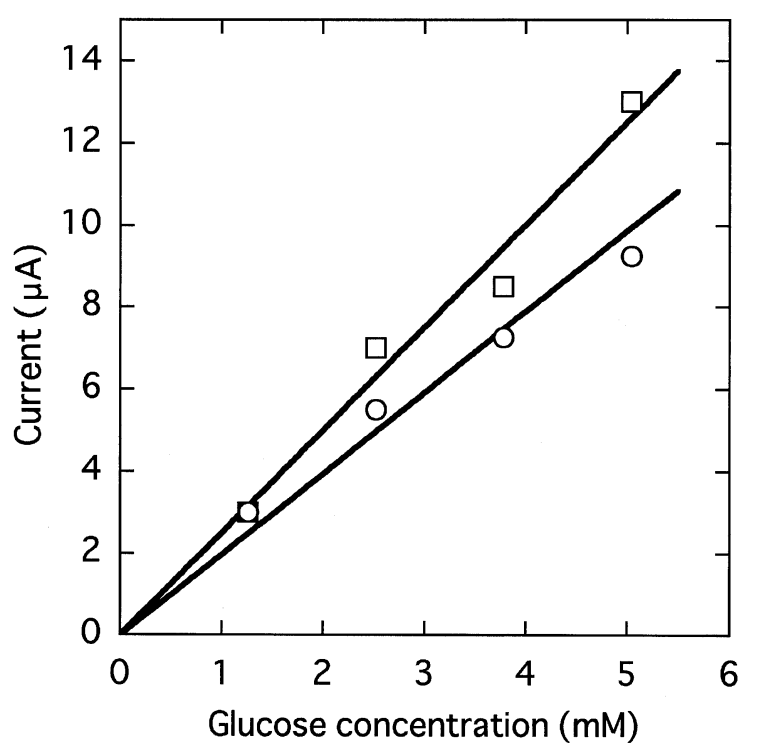

Figure 3. Relation between glucose concentration and response current of GOD-immobilized film of Copolymer 1, $\bigcirc$; Copolymer 2, $\square$.

of copolymer films carrying GOD. The conductivity of the copolymer films prepared in the present study (> $10^{-3} \mathrm{~S} \mathrm{~cm}^{-1}$ ) is thus sufficient for glucose sensing, and response current can be attributed to glucose oxidation by immobilized GOD.

\section{REFERENCES}

1. P. N. Bartlet and P. R. Birkin, Synth. Met., 61, 15 (1993).

2. P. N. Bartlet and P. R. Birkin, Anal. Chem., 66, 1552 (1994).

3. E. Tamiya and I. Karube, Sens. and Actuators, 15, 129 (1988).

4. M. Koudelka, S. Gernet, and N. F. de Rooji, Sens. and Actuators, 18, 157 (1989).

5. E. Tamiya, I. Karube, S. Hattori, M. Suzuki, and K. Yokoyama, Sens. and Actuators, 18, 297 (1989).

6. K. Kojima, T. Unuma, T. Yamauchi, M. Shimomura, and S. Miyauchi, Synth. Met., 85, 1417 (1997).

7. K. Kojima, T. Yamauchi, M. Shimomura, and S. Miyauchi, Polymer, 39, 2079 (1998).

8. N. C. Foulds and C. R. Lowe, J. Chem. Soc., Faraday Trans. 1, 82, 1259, (1986).

9. M. Umaña and J. Waller, Anal. Chem., 58, 2979 (1986).

10. K. Mosbach, Acta Chem. Scand., 24, 2084 (1970).

11. O. H. Lowry, N. J. Rosebrough, A. L. Farr, and R. J. Randall, J. Biol. Chem., 193, 265 (1951).

12. P. Trinder, Ann. Clin. Biochem., 6, 24 (1969).

13. K. Kojima, H. Nasu, M. Shimomura, and S. Miyauchi, Synth. Met., 71, 2245 (1995).

14. H. J. Bright and M. Appleby, J. Biol. Chem., 244, 3625 (1969).

15. M. Shimomura, H. Kikuchi, T. Yamauchi, and S. Miyauchi, J. Macromol. Sci., Pure Appl. Chem., A33, 1687 (1996). 